www.jmscr.igmpublication.org

Index Copernicus Value: 79.54

ISSN (e)-2347-176x ISSN (p) 2455-0450

crossref DOI: https://dx.doi.org/10.18535/jmscr/v7i4.66

\title{
Plasminogen Activator Inhibitor Type 1 in Patients with Alcoholic Liver Cirrhosis Associated with Non-alcoholic Fatty Liver Disease
}

\author{
Authors \\ Virstiuk Nataliia Hryhorivna ${ }^{1}$, Matkovska Nataliia Romanivna ${ }^{2 *}$ \\ ${ }^{1}$ Department of Internal Medicine of Stomatological Faculty, SHEE "Ivano-Frankivsk National Medical \\ University", Ministry of Health of Ukraine, Ivano-Frankivsk, Ukraine \\ ${ }^{2}$ Department of Therapy and Family Practice of postgraduate study faculty, SHEE "Ivano-Frankivsk \\ National Medical University", Ministry of Health of Ukraine, Ivano-Frankivsk, Ukraine \\ *Corresponding Author \\ Matkovska Nataliia Romanivna
}

Department of Therapy and Family Practice of postgraduate study faculty, SHEE "Ivano-Frankivsk National Medical University", Ivano-Frankivsk, Ukraine

Email:nmail4you@gmail.com

\begin{abstract}
The aim of the work was to study the changes of PAI-1 in patients with alcoholic liver cirrhosis (ALC) associated with non-alcoholic fatty liver disease (NAFLD), depending on the decompensation of the disease.

Material and Methods: 80 patients with ALC: 72 men and 8 women, aged 34 to 65 years were examined. Among them there were 38 patients with ALC (Group I) and 42 patients with ALC in combination with nonalcoholic fatty liver disease (NAFLD).

Results: An increase of PAI-1 content in the blood was found in patients with ALC, which increased with more pronounced decompensation of cirrhosis from A to B and C Child-Pugh Classes. The rate of PAI-1 was higher in a combination of ALC and NAFLD at all stages of the liver cirrhosis decompensation. The adverse effect of PAI-1 on the course of the ALC in combination with NAFLD according to correlation with the Child-Pugh score and the MELD index was revealed. We also interrelated the increasing content of PAI-1 in the blood of patients with ALC with concomitant NAFLD with indicators of immunoinflammatory system process (high-sensitivity C-reactive protein, tumour necrosis factor alpha), insulin resistance (immunoreactive insulin, HOMA-IR index) adipocytokines (leptin, adiponectin) endothelial dysfunction (asymmetric dimethylarinin).

Conclusion: Basing on the data of the study, it should be concluded that an increase in the content of PAI-1 adversely affects the course of the ALC with concomitant NAFLD, which substantiates the expediency of its use as a prognostic marker for such a cohort of patients.
\end{abstract}

Keywords: alcoholic liver cirrhosis, non-alcoholic fatty liver disease, plasminogen activator inhibitor type 1, decompensation, adipocytokines, endothelial dysfunction. 


\section{Introduction}

The medical and social value of the LC is determined by the growth of temporary disability, incapacitation and mortality of the population. LC is among the six main causes of death in patients aged $35-60$, which is $14-30$ cases per 100,000 population. LC ranks 4th in the world in the mortality structure of men over 40. Every year, about 2 million people die from its complications, it makes $71.0 \%$ of all digestive organs diseases ${ }^{[23]}$.

The nature of haemostasis in patients with LC is complicated and often unpredictable; it concerns all haemostasis links- vascular thrombocytic, coagulative, and fibrinolysis ${ }^{[5,10,17,18]}$. The severe complication of the $\mathrm{LC}$ is a bleeding from varices in the esophagus and stomach. The views on the mechanisms of development of this phenomenon have changed over the last decade, now such bleeding is considered not as a consequence of hypocoagulation, but as a consequence of hemodynamic disorders and portal hypertension ${ }^{[3,}$ ${ }^{24,26]}$. In recent years, a number of researchers have established the state of hypercoagulation in LC, which is the cause of intra-and extrahepatic thrombogenic states ${ }^{[2,15,19]}$. It is proved that patients with acute and chronic hepatic insufficiency are prone to have more often thromboembolism than spontaneous episodes of coagulopathic bleedings, as evidenced by the positive results of thromboprophylaxis ${ }^{[6,14,20,21]}$. Recently, the issue of the effectiveness of direct oral anticoagulants use in patients with LC has been discussed in order to prevent stroke, myocardial infarction, portal thrombosis, mesenteric vascular thrombosis and other thrombogenic conditions ${ }^{[2,12,13,22]}$.

The regulation of normal blood flow is performed by a fibrinolytic system, the main enzyme of which is plasmin. It is made up of plasminogen with serine proteases, such as tissue or urokinase plasminogen activator (t-PA and u-PA, respectively). On the contrary, fibrinolysis is inhibited by plasminogen activator inhibitor type 1 (PAI-1) ${ }^{[11]}$.

PAI-1 is a glycoprotein consisting of 379 amino acid residues with a molecular weight of $48 \mathrm{kDa}$. It is formed in endothelial cells, hepatocytes, adipocytes, monocytes, fibroblasts and can be released from thrombocytes in inactive form ${ }^{[12,15,20]}$. Reduced plasmin synthesis from plasminogen under PAI-1 influence leads to a slower rate of fibrin breakdown, a decrease in fibrinolysis, an increase in fibrinogen content and promotes thrombocytes aggregation. Therefore, PAI-1 is considered as a key component of the fibrinolysis system, an indicator of reduced fibrinolysis in particular, as well as a biochemical marker of endothelial dysfunction $^{[6,23,25]}$. Increased levels of PAI-1 in plasma are associated with a violation of fibrinolytic activity in stroke and $\mathrm{CHD}^{[6,25]}$. Moreover, levels of PAI-1 antigen and its activity are increased in patients with type 2 diabetes $^{[7]}$, hyper insulinemia ${ }^{[8]}$ and insulin resistance ${ }^{[9,16]}$.

The aim of the work is to study the changes of PAI-1 in patients with alcoholic liver cirrhosis (ALC) associated with non-alcoholic fatty liver disease (NAFLD), depending on the decompensation of the disease.

\section{Materials and Methods}

The subject of the study were 80 patients with ALC: 72 men and 8 women, aged 34 to 65 years. Among them there were 38 patients with ALC (Group I) and 42 patients with ALC in combination with nonalcoholic fatty liver disease (NAFLD), (Group II). ALC of Child-Pugh Classes A, B, and C was diagnosed in 16, 12 and 10 patients in Group I and 16, 14 and 12 patients in Group II. The control was 20 practically healthy persons.

The ALC was diagnosed according to the Adapted clinical guideline "Alcoholic Liver Disease" (State Expert Center of the Ministry of Health of Ukraine, Ukrainian Gastroenterological Association, Kyiv, 2014) and the Order of the Ministry of Health of Ukraine dated November 6, 2014, No. 826 of the protocol on medical care in the specialty "Alcoholic Hepatitis" ${ }^{[1]}$.

NAFLD was diagnosed according to the Adapted clinical guidelines "Non-Alcoholic Fatty Liver Disease" $^{\text {[28] }}$ and the Order of the Ministry of Health of Ukraine No. 826 dated November 6, 2014 
"Unified Clinical Protocol of Primary, Secondary (Specialized) Medical Aid: Non-Alcoholic Steatohepatitis" ${ }^{[28]}$, Recommendations of the European Association for the Study of the Liver (EASL), European Association for the Study of Diabetes (EASD), European Association for the Study of Obesity (EASO) ${ }^{[9]}$. The degree of gravity of the LC was assessed by Child-Pugh criteria (Child-Turcotte, Child-Turcotte-Pugh, ChildPaquet) ${ }^{[14]}$. MELD index (Mayo Endstage Liver Disease, 2001) was calculated; it is a prognostic index for liver disease calculating bilirubin level. International normalized ratio (INR) and serum creatinine were also calculated using an electronic calculator $^{[27]}$ :

MELD index $=3.8 \times \log _{\mathrm{e}}$ serum bilirubin level $(\mathrm{mg} / \mathrm{dl})+11.2 \times \log _{\mathrm{e}} \mathrm{INR}+9.6 \times \log _{\mathrm{e}}$ serum creatinine level (mg/dl).

All patients had general clinical examination (complaints analysis, life history, confirmation of alcoholic etiology of LC on the basis of international questionnaires CAGE, AUDIT and MAST, objective status, complete blood and urine tests, and blood chemistry), ultrasound of abdominal cavity, electro and echocardiography. To assess encephalopathy (EP) the criteria proposed by WestHaven were used ${ }^{[3]}$. The functional state of the liver was evaluated for the content of bilirubin, total protein and albumin, fibrinogen, aspartate aminotransferase (ASAT), alanine aminotransferase (ALAT), gamma-glutamyltranspeptidase (GGTP), alkaline phosphatase (AF) activity, using standard methods.

The content of PAI-1 in the blood was determined by the immunoassay method using Human PAI-1 Antigen ELISA, Technoclone (Austria).

The inflammatory process was evaluated by the content of high-sensitivity C-reactive protein (hsCRP) and TNF $\alpha$ in the blood, determined by the method of immunoassay analysis using Human hsCRP (high-sensitivity C-Reactive Protein) ELISA Kit (Elabscience, USA) and Human TNF-alpha High Sensitivity ELISA (Biovendor, Czech Republic) according to the manufacturer's methodology. Adipose tissue metabolism was evaluated by the content of adipocytokines - leptin and adeponectin; the presence of insulin resistance by the content of immunoreactive insulin (IRI) with the subsequent calculation of the index of insulin resistance (HOMA-IR); endothelial dysfunction, based on the content of asymmetric dimethylarginine (ADMA) in the blood, determined by the immune enzymatic method using Human Leptin ELISA (Biovendor, Czech Republic), Human Adiponectin ELISA kit (Biovendor, Czech Republic), "DRG Diagnostics" (Germany) and ADMA High Sensitive ELISA (Biovendor, Czech Republic), respectively.

The statistical processing of the results was carried out using the software package Statistica v. 12.0, Stat Soft, USA.

The study was carried out in accordance with the research plan of the SHEE "Ivano-Frankivsk National Medical University" and is a part of the research work on the topic: "Internal Organs Diseases in Modern Conditions Associated with Target Organs Pathology and Injury: Peculiarities of Course, Diagnosis and Treatment" (registration number 0115U000995).

\section{Results and Discussion}

According to the results of the study, the NAFLD was accompanied by a more severe ALC course by the Child-Pugh score and MELD index (Table 1), which were higher in Group II by $17.91 \%$ and $21.23 \%$ respectively $(\mathrm{p}<0.05)$, compared with those in Group I. These indices increased with increasing ALC decompensation in both Groups II and I, but the Child-Pugh score in Classes A, B and C was higher in Group II than that in patients of Group I of the corresponding Classes by $16.21 \% ; 18.03 \%$ and $11.53 \%$ respectively $(\mathrm{p}<0.05)$; the MELD index was also higher by $19.94 \% ; 21.03 \%$ and $16.35 \%$ respectively $(\mathrm{p}<0.05)$. 
Table 1: Parameters of the Alcoholic Liver Cirrhosis severity depending on the concomitant Non-alcoholic fatty liver disease and Child-Pugh class, $\mathrm{M} \pm \mathrm{m}$

\begin{tabular}{|c|c|c|}
\hline Groups of patients & $\begin{array}{c}\text { Child-Pugh } \\
\text { score }\end{array}$ & MELD index \\
\hline Group I (ALC), n=38 & $8.15 \pm 0.67$ & $15.59 \pm 0.79$ \\
\hline LCChild-PughClass A, $\mathrm{n}=16$ & $5.49 \pm 0.37$ & $10.53 \pm 0.62$ \\
\hline LCChild-PughClassB, $n=12$ & $7.82 \pm 0.49 \bullet$ & $16.07 \pm 0.83 \bullet$ \\
\hline LCChild-PughClassC, $\mathrm{n}=10$ & $12.75 \pm 0.58 \#^{\circ}$ & $23.43 \pm 1.30 \#^{\circ}$ \\
\hline Group I (ALC + NAFLD), n=42 & $9.61 \pm 0.72 *$ & $18.90 \pm 2.05^{*}$ \\
\hline LCChild-PughClass A, $n=16$ & $6.38 \pm 0.45^{*}$ & $12.63 \pm 0.68 *$ \\
\hline LCChild-PughClassB, $\mathrm{n}=14$ & $9.23 \pm 0.60 * \bullet$ & $19.45 \pm 1.17 * \bullet$ \\
\hline LCChild-PughClassC, $\mathrm{n}=12$ & $14.22 \pm 0.71^{*} \#^{\circ}$ & $27.26 \pm 1.45^{*} \#^{\circ}$ \\
\hline \multicolumn{3}{|c|}{$\begin{array}{l}\text { Notes: } * \text { - the reliability of the parameters difference in Group II } \\
\text { compared with Group I of the corresponding Child-Pugh classes; }- \\
\text { the reliability of the parameters difference of class B compared with } \\
\text { class A in Groups I and II, respectively, } \mathrm{p}<0.05 \text {; } \#-\text { the reliability of } \\
\text { the parameters difference between the classes C and A in Groups I } \\
\text { and II, respectively, p }<0.05 \text {; }{ }^{-} \text {the reliability of the parameters } \\
\text { difference between the classes C and B in Groups I and II, } \\
\text { respectively, }<<0.05 \text {. }\end{array}$} \\
\hline
\end{tabular}

The functional state of the liver was mostly deteriorated in patients with ALC in combination with NAFLD (Table 2). In particular, the activity of ASAT and ALAT in patients of Group II was higher in comparison with patients of Group I of ChildPugh Class A by $18.46 \%$ and $45.0 \%$ ( $\mathrm{p}<0.05$ ); Class B - 30.23\% and 30.14\% ( $<<0.05)$; Class C $19.17 \%$ and $48.30 \%$ ( $<<0.05$ ); the bilirubin content - 32.82\%, $21.40 \%$ and $26.62 \%$ respectively $(\mathrm{p}<0.05)$, indicating a greater severity of the cytolytic syndrome. The content of total protein and albumin was lower in patients of Group II compared to patients of Group I of Chuild-Pugh Class A - by $9.61 \%$ and $10.44 \%$ ( $\mathrm{p}<0.05$ ); ClassB-by $10.95 \%$ and $14.98 \%$ (p <0.05); ClassC -by $10,48 \%$ and $14,84 \%$ ( $\mathrm{p}<0,05)$, indicating a more severe disorder of the synthesizing liver function in concomitant NAFLD. The content of fibrinogen was higher in patients of Group II compared to patients of Group I of Child-Pugh Class A by 2.15 times $(\mathrm{p}<0.05)$; Class B-by 1.84 times $(\mathrm{p}<0.05)$ and id not differ significantly in the terminal stage of the ALC of ClassC ( $p>0.05$ ), which may be due to a higher level of inflammatory process and a higher risk of thrombotic conditions in NAFLD at compensation and decompensation stages of the ALC. The activity of GGTP and AF in patients of Group II was higher in comparison with patients of Group I Child-Pugh Class A by $49.34 \%$ and $13.61 \%(\mathrm{p}<0.05)$; Class B by $36.53 \%$ and $30.23 \%$ ( $<<0.05)$; ClassC $-25.03 \%$ and $18.41 \% \quad(\mathrm{p}<0.05)$, which indicates a higher incidence of cholestatic syndrome. The content of fibrinogen was higher in patients of Group II Class A Child-Pugh by 2.15 times $(\mathrm{p}<0.05)$; Class B 1.84 times $(p<0.05)$ and did not differ significantly in the terminal stage of ALC for Class C ( $p>0.05)$, which may be due to a higher level of inflammatory process and a higher risk of thrombotic conditions because of NAFLD at the stage of compensation and decompensation of the ALC. The indicator of INR increased with increasing decompensation of ALC ( $\mathrm{p}<0.05)$, indicating hepatic impairment; its differences in patients of both groups were not detected $(\mathrm{p}>0.05)$.

All patients with ALC had the activation of the systemic immune-inflammatory process with an increase in the content of hs-CRP and TNF $\alpha$ compared with healthy ones $(\mathrm{p}<0.05)$, but these changes were greater with concomitant NAFLD at all stages of decompensation (Table 3). In particular, the content of hs-CRP and TNFa in the blood of patients of Group II was higher compared to patients of Group I of Child-Pugh Class A by $57.26 \%$ and $50.84 \%(\mathrm{p}<0.05)$; Class B - by $44.75 \%$ and $55.35 \%(\mathrm{p}<0.05)$; Class C - by $42.43 \%$ and $46.10 \%$ $(\mathrm{p}<0.05)$. Manifestations of insulin resistance were observed in patients of Group II with an increase of IRI and HOMA-IR in the content compared with healthy people $(\mathrm{p}<0.05)$, which grew from $A$ to $B$ ALC class $(p<0.05)$ and remained the same for the Class C of ALC ( $p>0.05)$; which was not detected in patients of Group I.

The imbalance of adipocytokines was more pronounced in patients with ALC in combination with concomitant NAFLD. In particular, the content of leptin in the blood of patients of Group II was higher compared to those in Group I of Child- 
Table 2: Indicators of the functional state of the liver in patients with alcoholic liver cirrhosis depending on the concomitant non-alcoholic fatty liver disease and Child-Pugh class, $\mathrm{M} \pm \mathrm{m}$

\begin{tabular}{|c|c|c|c|c|c|c|c|}
\hline \multirow{2}{*}{$\begin{array}{l}\text { Indicators, } \\
\text { units }\end{array}$} & \multirow{2}{*}{$\begin{array}{c}\text { Healthy, } \\
n=20\end{array}$} & \multicolumn{2}{|c|}{ Class A } & \multicolumn{2}{|c|}{ Class B } & \multicolumn{2}{|c|}{ Class C } \\
\hline & & $\begin{array}{c}\text { Group I, } \\
n=16\end{array}$ & $\begin{array}{c}\text { Group II, } \\
n=16\end{array}$ & $\begin{array}{c}\text { Group I, } \\
n=12\end{array}$ & $\begin{array}{c}\text { Group II, } \\
n=14\end{array}$ & $\begin{array}{c}\text { Group I, } \\
n=10\end{array}$ & $\begin{array}{c}\text { Group II, } \\
\mathrm{n}=12\end{array}$ \\
\hline $\begin{array}{l}\text { Total } \\
\text { bilirubin, } \mu \\
\text { mol/l }\end{array}$ & $13.52 \pm 1.28$ & $22.73 \pm 1.61 *$ & $30.19 \pm 1.82 * \bullet$ & $55.51 \pm 2.75 * \diamond$ & $43.63 \pm 1.27 * \bullet \diamond$ & $105.31 \pm 4.60^{* \#^{\circ}}$ & $132.29 \pm 5.91 * \bullet \#^{\circ}$ \\
\hline $\begin{array}{l}\text { AsAT.mmo } \\
1 / \mathrm{h} * 1\end{array}$ & $0.28 \pm 0.01$ & $0.65 \pm 0.02 *$ & $0.77 \pm 0.04 * \bullet$ & $0.86 \pm 0.05 * \diamond$ & $1.12 \pm 0.06 * \bullet \diamond$ & $1.20 \pm 0.07 * \#^{\circ}$ & $1.43 \pm 0.09 * \bullet *^{\circ}$ \\
\hline $\begin{array}{l}\text { AlAT.mmo } \\
\text { l/h*1 }\end{array}$ & $0.25 \pm 0.01$ & $0.40 \pm 0.01^{*}$ & $0.58 \pm 0.02 * \bullet$ & $0.73 \pm 0.03 * \diamond$ & $0.95 \pm 0.05 * \bullet \diamond$ & $0.89 \pm 0.04 * \#^{\circ}$ & $1.32 \pm 0.08 * \bullet \#^{\circ}$ \\
\hline $\begin{array}{l}\text { GGTP. } \\
\mathrm{mmol} / \mathrm{h} * 1\end{array}$ & $4.85 \pm 0.02$ & $12.16 \pm 0.57 *$ & $18.16 \pm 0.64 * \bullet$ & $19.08 \pm 0.72 * \diamond$ & $26.05 \pm 1.07 * \bullet \diamond$ & $24.73 \pm 0.95^{*} \#^{\circ}$ & $30.92 \pm 0.95^{*} \bullet \#^{\circ}$ \\
\hline $\begin{array}{l}\mathrm{AF} . \\
\mathrm{mmol} / \mathrm{h} * 1\end{array}$ & $1.20 \pm 0.06$ & $3.38 \pm 0.10^{*}$ & $3.84 \pm 0.15^{* \bullet}$ & $4.30 \pm 0.21 * \diamond$ & $5.17 \pm 0.24 * \bullet \diamond$ & $5.05 \pm 0.27 * \#^{\circ}$ & $5.98 \pm 0.30 * \bullet \#^{\circ}$ \\
\hline $\begin{array}{l}\text { Totalprotei } \\
\text { n. g/l }\end{array}$ & $75.67 \pm 1.27$ & $65.38 \pm 1.97 *$ & $59.10 \pm 2.04 * \bullet$ & $58.53 \pm 1.83 * \diamond$ & $52.12 \pm 1.66 * \bullet \diamond$ & $50.47 \pm 2.12 * \#^{\circ}$ & $45.18 \pm 2.10 * \bullet \#^{\circ}$ \\
\hline $\begin{array}{l}\text { Albumin. } \\
\mathrm{g} / \mathrm{l}\end{array}$ & $47.83 \pm 1.26$ & $37.25 \pm 1.12 *$ & $33.36 \pm 1.15 * \bullet$ & $32.50 \pm 1.24 * \diamond$ & $27.63 \pm 1.30 * \bullet \diamond$ & $26.35 \pm 1.22 * \#^{\circ}$ & $22.44 \pm 1.20 * \bullet \#^{\circ}$ \\
\hline $\begin{array}{l}\text { Fibrinogen. } \\
\mathrm{g} / \mathrm{l}\end{array}$ & $2.46 \pm 0.16$ & $1.93 \pm 0.13 *$ & $4.15 \pm 0.22 * \bullet$ & $1.60 \pm 0.12 * \diamond$ & $2.95 \pm 0.14 * \bullet \diamond$ & $1.28 \pm 0.10^{*} \#^{\circ}$ & $1.35 \pm 0.11^{*} \#^{\circ}$ \\
\hline INR & $1.18 \pm 0.05$ & $1.27 \pm 0.06^{*}$ & $1.25 \pm 0.09 *$ & $1.62 \pm 0.08 * \diamond$ & $1.55 \pm 0.14 * \diamond$ & $2.07 \pm 0.14 * \#^{\circ}$ & $2.20 \pm 0.15^{*} \#^{\circ}$ \\
\hline
\end{tabular}

Notes: $*$ - the reliability of the differences between Groups I and II compared with healthy persons. $\bullet-$ the reliability of the indicators difference in Group II compared with Group I of the corresponding Child-Pugh Classes. $\diamond-$ the reliability of the indicators difference of Class B compared with Class A in Groups I and II, respectively. p<0.05; \# - the reliability of the indicators difference of Class C compared with Class A in Groups I and II, respectively. $\mathrm{p}<0.05$; ${ }^{\circ}$ the reliability of the indicators difference of Class C compared with Class B in Groups I and II, respectively. $\mathrm{p}<0.05$.

Pugh Classes A, B and C by $2.50 \%, 2.94$ and 3.24 times, respectively $(\mathrm{p}<0.05)$. The content of adiponectin was lower compared to patients in Group I of Child-Pugh Classes A, B and C, by $18.50 \%, 34.72$ and $20.78 \%$, respectively $(\mathrm{p}<0.05)$.

According to the dynamics of the ADMA index, all patients with ALC had endothelial dysfunction, which was more pronounced in combination with concomitant NAFLD. In particular, ADMA content in patients of Group II of Child-Pugh Classes A, B and $\mathrm{C}$ was higher than in patients of Group $\mathrm{I}$ at $2.17 \%, 1.92$ and 1.44 times, respectively ( $p<0.05$ ).

According to the results of the study, it was found that the content of PAI- 1 in the blood of patients of Group II was $(70.8 \pm 2.6) \mathrm{ng} / \mathrm{ml}$ and exceeded that in Group I $(54.3 \pm 2.2) \mathrm{ng} / \mathrm{ml}$ by $30.39 \%(\mathrm{p}<0.05)$ and the indicator in healthy persons was $(18.36 \pm 0.72) \mathrm{ng} / \mathrm{ml}(\mathrm{p}<0.05)$. The content of IAP-1 in the blood of patients in Group I of Child-Pugh Classes A, B and C exceeded that in healthy people at 2.03, 2.70 and 2.73 times, respectively $(p<0.05)$. The content of PAI-1 in the blood of patients in Group II was higher and in A, B and C Child-Pugh classes, it exceeded that in healthy people at 3.11 ,
3.72 and 3.47 times, respectively ( $\mathrm{p}<0.05)$; this indicator was higher than that in patients of Group I by $53.48 \%, 37.76 \%$ and $27.21 \%$ respectively $(\mathrm{p}<0.05)$.

Patients with ALC with concomitant NAFLD showed correlations between PAI-1 and immunoinflammatory system process indices -hs-CRP, TNF $\alpha \quad(r=0.68 ; r=+0.73$, respectively, $\mathrm{p}<0.05)$; between PAI-1 and parameters of insulin resistance - IRI and HOMA-IR $(\mathrm{r}=+0.52 ; \mathrm{r}=+0.75$, respectively, $\mathrm{p}<0.05)$; between PAI-1 and adipocytokin indices - leptin and adiponectin $(\mathrm{r}=+0.63 ; \mathrm{r}=-0.81$, respectively, $\mathrm{p}<0.05)$; between PAI-1 and the index of endothelial dysfunction of ADMA $\quad(\mathrm{r}=+0.65 ; \mathrm{p}<0.05)$ indicating the connection of PAI-1 with various pathogenetic links of ALC in combination with NAFLD. The revealed correlations can be explained by the fact that in pathological conditions, the synthesis of PAI-1 can be activated by proinflammatory factors, in particular, TNF $\alpha$, growth factors, in particular the transforming factor of beta growth (TFR $\beta$ ) and insulin $^{[6]}$. A number of researchers point out that an increase in PAI-1 levels can cause hypercoagulation $^{[2]}$, and therefore its increase in 
patients with ALC in combination with NAFLD can predict the risk of thrombogenic conditions.

Correlation between PAI-1 and ALC severity Child-Pugh and MELD index ( $\mathrm{r}=-0.71 ; \mathrm{r}=-0.68$ respectively, $\mathrm{p}<0.05$ ) was found, which confirms the adverse effect of PAI- 1 on the progress of the ALC in combination with NAFLD and justifies the feasibility of its use as a prognostic marker in such patients.

\section{Conclusions}

1. Patients with ALC showed an increase in the content of PAI-1 in the blood, increasing for more severe decompensation of cirrhosis from A to B and C Child-Pugh Classes. The PAI-1 parameter was greater than the combination of ALC and NAFLD at all stages of liver cirrhosis decompensation. 2. We revealed the adverse effect of PAI-1 on the course of ALC in combination with NAFLD according to the correlation with the Child-Pugh score and the MELD index. 3. We interrelated the increasing content of PAI-1 in the blood of patients with ALC with concomitant NAFLD with the parameters of the immune-inflammatory system process (hs-CRP, $\mathrm{TNF} \alpha$ ), insulin resistance (IRI, HOMA-IR), adipocytokines (leptin, adiponectin), endothelial dysfunction (ADMA).

\section{References}

1. Alkogol naxvorobapechinky`. Adaptovanaklinichnanastanova, zasnovananadokazax, [Elektronny` jresurs] (2014). Rezhy` mdostupu do resursu: http://moz.gov.ua/docfiles/dod_akn_dn_201 40616_1.pdf.

2. Ambrosino P, Tarantino L, Di Minno G, et al. The risk of venous thromboembolism in patients with cirrhosis. A systematic review and meta-analysis. Thromb Haemost 2017; 117:139.

3. American Association for the Study of Liver Diseases (2014).Hepatic encephalopathy in chronic liver disease: 2014 practice guideline by the European Association for the Study of the Liver and the American
Association for the Study of Liver Diseases.

J. Hepatol. 61: 642-659.

Doi:ncbi.nlm.nih.gov/pubmed/25015420.

4. Blasi A. Coagulopathy in liver disease: Lack of an assessment tool. World $\mathrm{J}$ Gastroenterol. 2015 Sep 21; 21(35): 1006210071. doi: 10.3748/wjg.v21.i35.10062

5. Davis JPE, Northup PG, Caldwell SH, Intagliata NM. Viscoelastic Testing in Liver Disease. Ann Hepatol 2018; 17:205.

6. Dirkmann D. The Hemostatic System in Patients with Cirrhosis, Monitoring of Coagulation and Management of Bleeding. In book: Critical Care for Potential Liver Transplant Candidates. 2019. DOI: 10.1007/978-3-319-92934-7_7

7. EASL Clinical Practical Guidelines: Management of AlcoholicLiver Disease, 2012 /Journal of Hepatology. -2012. Vol.57. - P.399-420. Doi: http://www.spg.pt/wpcontent/uploads/2015/11/2012-ALD.pdf

8. EASL Clinical Practice Guidelines for the management of patients with decompensated cirrhosis. J Hepatol 2018, 69 (2): 406-460. DOI: https://doi.org/10.1016/j.jhep.2018.03. 024

9. EASL-EASD-EASO Clinical Practice Guidelines for the management of nonalcoholic fatty liver disease (2016) Journalof Hepatology64(6):1388-1402

10. Fisher C, Patel VC, Stoy SH, et al. Balanced haemostasis with both hypo- and hypercoagulable features in critically ill patients with acute-on-chronic-liver failure. J Crit Care 2018; 43:54.

11. Fuentes A, Gordon-Burroughs S, Hall JB, et al. Comparison of anti-Xa and activated partial thromboplastin time monitoring for heparin dosing in patients with cirrhosis. Ther Drug Monit 2015; 37:40.

12. Hum J, Shatzel JJ, Jou JH, Deloughery TG. The efficacy and safety of direct oral anticoagulants vs traditional anticoagulants in cirrhosis. Eur J Haematol 2017; 98:393. 
13. Intagliata NM, Henry ZH, Maitland H, et al. Direct Oral Anticoagulants in Cirrhosis Patients Pose Similar Risks of Bleeding When Compared to Traditional Anticoagulation. Dig Dis Sci 2016; 61:1721.

14. Intagliata NM, Maitland H, Caldwell SH. Direct oral anticoagulants in cirrhosis. Curr Treat Options Gastroenterol 2016; 14:247.

15. Intagliata NM, Maitland $H$, Northup PG, Caldwell SH. Treating thrombosis in cirrhosis patients with new oral agents: ready or not? Hepatology 2015; 61:738.

16. Kalambokis GN, Oikonomou A, Christou L, et al. von Willebrand factor and procoagulant imbalance predict outcome in patients with cirrhosis and thrombocytopenia. J Hepatol 2016; 65:921.

17. Lisman $\mathrm{T}$, Bos $\mathrm{S}$, Intagliata NM. Mechanisms of enhanced thrombingenerating capacity in patients with cirrhosis. J Thromb Haemost 2018; 16:1128.

18. Luyendyk JP, Schoenecker JG, Flick MJ.The multifaceted role of fibrinogen in tissue injury and inflammation. Blood. 2019 Feb 7; 133(6):511-520. Epub 2018 Dec 6.

19. Ng KJ, Lee YK, Huang MY, et al. Risks of venous thromboembolism in patients with liver cirrhosis: a nationwide cohort study in Taiwan. J ThrombHaemost 2015; 13:206.

20. Qamar A, Vaduganathan M, Greenberger NJ, Giugliano RP. Oral Anticoagulation in Patients With Liver Disease. J Am Coll Cardiol 2018; 71:2162.

21. Shatzel J, Dulai PS, Harbin D, et al. Safety and efficacy of pharmacological thromboprophylaxis for hospitalized patients with cirrhosis: a single-center retrospective cohort study. J Thromb Haemost 2015; 13:1245.

22. Sinegre T, Duron C, Lecompte $\mathrm{T}$, et al. Increased factor VIII plays a significant role in plasma hyper coagulability phenotype of patients with cirrhosis. J Thromb Haemost 2018; 16:1132.
23. Stepanov YuM, Gravirovs` ka NG (2012) Dy`namikazaxvoryuvanosti ta poshy renostiosnovny`xxvoroborganivtravlennya $\mathrm{v}$ Ukrayini za 5 ostannixrokiv. Gastroenterologiya: mizhvid. Zbirny`k, Dnipro: Zhurfond, 46: 3-12.

24. Stine JG, Shah NL, Argo CK, et al. Increased risk of portal vein thrombosis in patients with cirrhosis due to nonalcoholic steatohepatitis. Liver Transpl 2015; 21:1016.

25. Transplant Direct. 2018 Nov; 4(11):e403. Epub 2018 Oct 26.

26. Verbeek TA, Stine JG, Saner FH, Bezinover D.Hypercoagulability in End-stage Liver Disease: Review of Epidemiology, Etiology, and Management.

27. Xobzej MK, Xarchenko NV, Lishhy`shy`na OM ta in (2014) Unifikovany` jklinichny` jprotokol "Alkogol`ny` jsteatogepaty`t". Nakaz MOZ Ukrayiny \# 826 vid 06.08.2014 roku [Elektronny’jresurs]. Rezhy`mdostupu: http://mtd.dec.gov.ua/images/dodatki/2014_ 826Gepatyty/2014_826_YKPMD_AG.pdf

28. Xobzej MK, Xarchenko NV, Lishhy`shy`na OM ta in (2014) Unifikovany` jklinichny jprotokol "Nealkogol ny`j steatogepaty`t". Nakaz MOZ Ukrayiny` \# 826 vid 06.11.2014 roku [Elektronny` jresurs]. Rezhy`m dostupu: http://moz.gov.ua/docfiles/dn_20141106_08 26_dod_ukp_nsg.pdf 